\title{
An Integrated Approach for Drilling Optimization Using Advanced Drilling Optimizer
}

\author{
David Hankins, Saeed Salehi, and Fatemeh Karbalaei Saleh \\ Petroleum Engineering Department, University of Louisiana at Lafayette, Lafayette, LA 70504, USA \\ Correspondence should be addressed to Saeed Salehi; saeads@gmail.com
}

Received 13 September 2014; Accepted 5 December 2014

Academic Editor: Merv Fingas

Copyright (C) 2015 David Hankins et al. This is an open access article distributed under the Creative Commons Attribution License, which permits unrestricted use, distribution, and reproduction in any medium, provided the original work is properly cited.

\begin{abstract}
The ability to optimize drilling procedures and economics involves simulation to understand the effects operational parameters and equipment design have on the ROP. An analysis applying drilling performance modeling to optimize drilling operations has been conducted to address this issue. This study shows how optimum operational parameters and equipment can be predicted by simulating drilling operations of preexisting wells in a Northwest Louisiana field. Reference well data was gathered and processed to predict the "drillability" of the formations encountered by inverting bit specific ROP models to solve for rock strength. The output data generated for the reference well was formatted to simulate upcoming wells. A comparative analysis was conducted between the predicted results and the actual results to show the accuracy of the simulation. A significant higher accuracy is shown between the simulated and actual drilling results. Once simulations were validated, optimum drilling parameters and equipment specifications were found by varying different combinations of weight on bit (WOB), rotary speed (RPM), hydraulics, and bit specifications until the highest drilling rate is achieved for each well. A qualitative and quantitative analysis of the optimized results was conducted to assess the potential operational and economic benefits on drilling operations.
\end{abstract}

\section{Introduction}

As companies continue to expand their drilling operations within existing oil and gas fields across the world, now is the time to maximize profitability by optimizing drilling operations to reduce the associated costs. In order to optimize upcoming wells it is important to understand (1) problems encountered during previously drilled wells in the same field, (2) the effects drilling parameters and equipment specifications have on drilling performance, (3) methods of determining the formation strength or "drillability" encountered in the wellbore, and (4) the applications of drilling optimizer in simulating upcoming wells. Knowing when inadequate equipment and operational parameters are being implemented in the drilling procedure as well as avoiding their use allows for drilling and economic optimization. This approach was applied to a well-developed field located in Northwest Louisiana where nonproductive time (NPT) and unnecessary costs occurred due to insufficient operational parameters and equipment specifications implemented in the drilling process.
Often times in heavily produced fields the drilling process has become a standard routine procedure, especially on land. Increasing drilling performance and minimizing costs in any drilling operation begin with an accurate understanding of the lithological characteristics encountered in the wellbore, more importantly the formation rock strength or "drillability" [1]. Having an accurate estimation of these parameters is vital to reducing costs by improving the overall drilling performance of any well.

Typical methods used to predict rock strength involve mechanical testing on physical cored rock samples [2], testing on rock cuttings [3], evaluating sonic logs [4], and ROP modeling analyses [5]. ROP modeling has come a long way since Maurer [6] first presented his "perfect-cleaning" theory for roller-cone bits. In 1994, Hareland and Rampersad presented the standard ROP model for polycrystalline-diamond compact (PDC) bits. The key factor of these ROP models is based off of the strength of the formations encountered during drilling.

While these models are applied to predict the ROP based off of bit design/specifications, operational parameters, and 


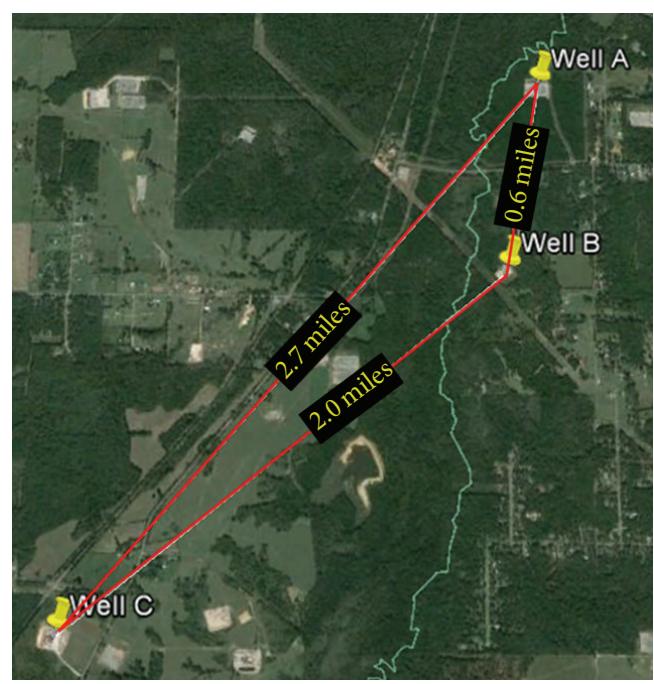

FIGURE 1: Satellite imagery of the well locations.

formation characteristics, their inversion could be solved to find the confined compressive strength or "drillability" of the formation [7, 8]. Optimizer generates an Apparent Rock Strength Log (ARSL) of the rock "drillability" for every foot of the wellbore by utilizing data from an offset well [9]. This ARSL can then be used to simulate and optimize upcoming wells within the same field by showing the effects changing operational parameters and equipment designs can have on the overall drilling performance[7, 8]. As more wells in the same field are added in the optimizer for reference, the accuracy of the simulations produced will continue to increase.

\section{Field Overview}

The field of study is located in Northwest Louisiana. For confidentiality purposes, the name of the field, wells, and formations included within this study have been changed. The main area of interest is the wellbore sections drilled with an $8.75^{\prime \prime}$ PDC bit for each of the three proposed wells: Well A, Well B, and Well C. This section was chosen for analysis due to the similarities between each well and because measured depth (MD) can be assumed as true vertical depth (TVD) since the inclination of this section is less than $1^{\circ}$ for each well. The three wells are located within the same field and are no more than 2.7 miles apart from one another (Figure 1). Consequently, the same formations were encountered during the drilling of this section between each well. The formations encountered during drilling were comprised predominantly of limestone, shale, and sandstone that range from Upper Jurassic to Lower Cretaceous in age.

Well A was used as the reference well in this study. The $8.75^{\prime \prime}$ section of Well A was drilled from 2401 to 8999 feet MD. Ten formations were encountered during drilling for this section of the well. Once analyzed, the results produced from Well A were used to simulate Well B.

Well B was simulated by matching its formation tops with those of Well A. This $8.75^{\prime \prime}$ section is shorter for Well B stretching from only 2373 to 7949 feet MD. Consequently, only eight of the formations encountered during Well A will be drilled in this section of Well B. Once simulated, the results were compared to the actual drilling data so that accuracy of the simulation is analyzed when only one well is used for reference.

Well C was simulated utilizing data obtained from both Well A and Well B for reference. The $8.75^{\prime \prime}$ section of Well C was drilled from 2367 to 9097 feet MD. This section of the well is similar to Well A with nine of the same formations encountered during drilling. The simulated results were then compared with the actual drilling results to determine the accuracy when two wells are used for reference.

Once simulated results had been validated, each well was optimized by utilizing optimizer. The $8.75^{\prime \prime}$ section of each well was divided into different sections based off the formations encountered so simulations could be conducted to find the most efficient drilling parameters and equipment design for each formation. Once separated, each formation was optimized by running simulations with different WOB/RPM combinations, bit specifications, and hydraulics until the most efficient and cost effective parameters are reached. Upon completion, a cost analysis was conducted to show the effectiveness drilling simulation can have on optimizing drilling operations in this Northwest Louisiana field.

\section{Factors Affecting the Penetration Rate in PDC Bits}

PDC bits get their name from their drill blank cutting elements that consist of a layer of synthetic polycrystalline diamond that is attached to tungsten carbide in a highpressure/high-temperature (HPHT) process [10]. Trying to select a PDC bit when you have multiple manufacturers to choose from can be a difficult task for the operator $[1,11]$. Knowledge of the design features and operational conditions is imperative when optimizing wellbore sections that are drilled with PDC bits.

The design features of PDC bits are one of the main factors affecting the ROP. Each PDC bit used to drill a well is chosen specifically for the application at hand. Therefore, it is important to understand how variations in PDC design features and specifications can affect the drilling rate. The ROP can vary significantly with changes in size of the bit, number of cutters, back-rake angle, side-rake angle, and junk-slot area (Figure 2).

PDC bit size and junk-slot area have the most significant effect on drilling performance. However, the back-rake angle of the cutters and the number of cutters located on the bit have a moderate effect on the ROP. The side-rake angle of a PDC bit's cutters has a minor effect of drilling performance.

The ability for the PDC bit's design featuresto cut hole efficiently depends on the operational parameters acting upon them. Changes in drilling operational parameters can have a major effect on the drilling rate (Figure 3). Therefore, it is important to understand how each operational parameter used while drilling can affect the drilling rate. An assessment 


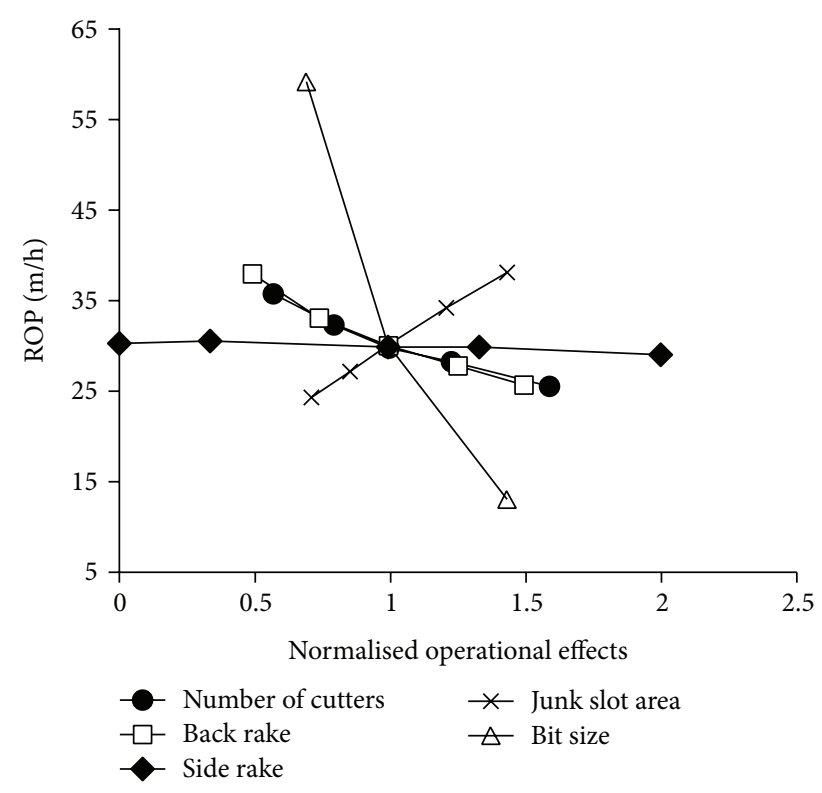

Figure 2: Normalised bit design parameter effect on ROP [7, 8].

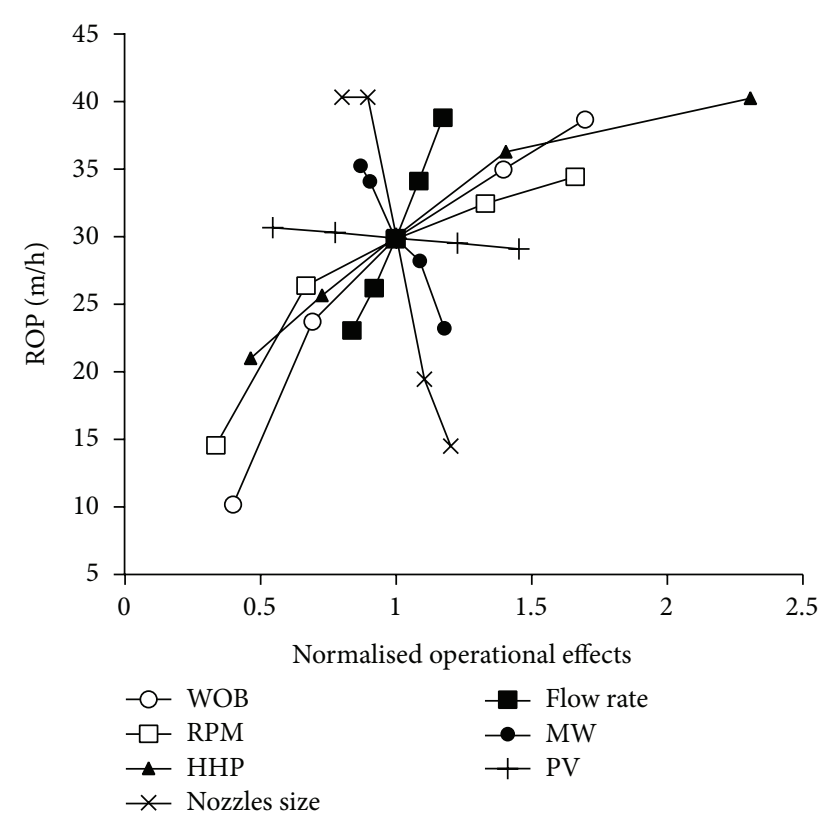

FIGURE 3: Normalised operational effects on ROP $[7,8]$.

has been conducted to present a generalized understanding the effect weight on bit (WOB), rotary speed (RPM), and hydraulics and mud characteristics have on the drilling performance.

Increasing weight on bit (WOB) and rotary speed (RPM) have a significant effect on drilling performance. This is due to the fact that as WOB increases the teeth are pushed deeper into the formation and as RPM increases the cutting rotations are increased. However, bit hydraulics must be adjusted to ensure cuttings do not impede the bit to formation contact.

\section{Modeling Drilling Performance from Rock Strength}

Over the past decades, several methods have been developed to estimate ROP [12]. These models are able to predict ROP from operational parameters and formation characteristics. Additionally, the inversion of these models can be used to predict the rock strength or "drillability" [9]. Once rock strength is established, other operational parameters can be changed to estimate the effects it may have on the drilling performance. This can have a significant effect on optimizing drilling operations [13].

In 1994, Hareland and Rampersad presented a new model to predict the ROP of PDC bits that take into account the interaction between the cutter and rock, lithology, and bit wear. New parameters are introduced for the equivalent bit radius, dynamic cutter action, lithology coefficients, and cutter wear (1). Consider

$$
\mathrm{ROP}=\frac{14.14 * \mathrm{WOB} * \mathrm{ROP} * \cos \alpha}{S * d_{b} * \tan \Theta} * \frac{a}{\mathrm{RPM}^{b} * \mathrm{WOB}^{c}} .
$$

In (1), ROP is rate of penetration, WOB is weight on bit, $S$ is drillability strength of the rock, $d_{b}$ is bit diameter, $\alpha$ is the cutter side-rake angle, $\Theta$ is the cutter back-rake angle, and $a$, $b$, and $c$ are cutter geometry correction factors. Additionally, rock strength can be estimated by solving for the inversion of (1) as in the following equation:

$$
S=\frac{14.14 * \mathrm{WOB} * \mathrm{RPM} * \cos \alpha}{\mathrm{ROP} * d_{b} * \tan \Theta} * \frac{a}{\mathrm{RPM}^{b} * \mathrm{WOB}^{c}} .
$$

\section{Optimization Workflow}

The workflow was used for the optimization process in this paper as shown in Figure 4.

Here we describe the workflow in detail.

\section{Data Processing and Study}

The initial phase involves gathering necessary data from preexisting well(s) that were drilled within the particular field of interest. Necessary data includes operational parameters, bit design, and specifications, as well as lithologic information encountered during drilling. This preexisting data is of significant importance since it is used to predict the results of different drilling scenarios when planning new wells [1]. It is important that the well(s) used as a reference is a close match to the upcoming well so there are no major discrepancies between the planned and actual drilling results. Data is organized and input into the necessary file type in order for the optimizer to generate a simulation for upcoming wells. These files include $\langle$ BIT $\rangle,\langle$ LITH $\rangle$, and $\langle$ DRILL $\rangle$.

Necessary data needed to be input into the bit file was found from the daily drilling reports and design specifications provided by the bit manufacturer. Generation of the bit file includes information such as bit size, depth in/out, bit wear in/out, and number/size of nozzles. In addition, since 


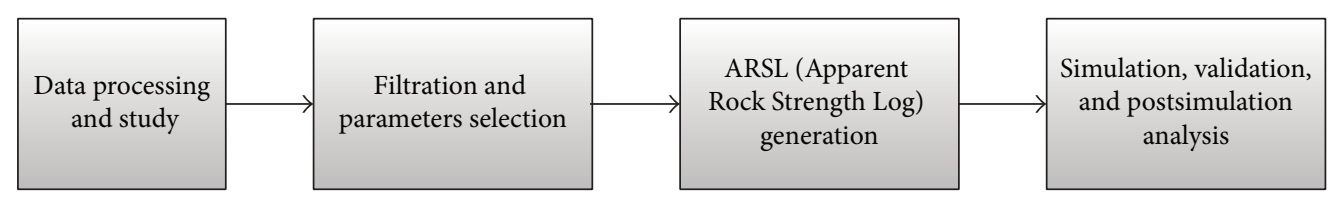

Figure 4

PDC bits are being used in the simulation, cutter specifications including number/size of cutters, back-rake/side-rake angle, number of blades, and junk slot area were also needed [14]. The optimizer predicts drilling performance and bit wear for each bit based on their design specifications [11]. Therefore, it is imperative that all data input into the $\langle\mathrm{BIT}\rangle$ file was accurate prior to running the simulation to ensure the validity of the results.

Input data needed for the 〈DRILL〉 file can be found in the drilling reports of the reference well(s). Drilling recorders located on the rig have taken note of all operational parameters for every foot of the drilling process. Necessary data includes MD/TVD, ROP, WOB, RPM, flow rate, and mud characteristics/type. An extensive quality control procedure was done on the drill file data to remove any erroneous data entry that is not within the acceptable range. Each acceptable range is defined by standards set by the rig, equipment, or personnel to ensure equipment is being used to their designed parameters and that safe drilling practices are being followed at all times. When data points did not fall within the acceptable range they were removed and the data was averaged between the last closest acceptable data points [14].

The final file needed to run the optimizer is the $\langle$ LITH $\rangle$ file. In order to generate the lithology file, the top depths and lithologic descriptions were input for every formation encountered when drilling the reference well. The necessary data can usually be found from geology reports or generated based on log properties [14]. Mud logs are a good data source since they record lithologic percentages of the cuttings along with relevant mud properties for every foot of the drilling operation. Data input into the lithology file includes MD/TVD, percentages of lithology, formation pore pressure, and permeability.

\section{Generating the ARSL}

Once the $\langle\mathrm{BIT}\rangle,\langle\mathrm{DRILL}\rangle$, and $\langle\mathrm{LITH}\rangle$ files had been completed and validated they were used to create an ARSL for every foot of the reference well. Additionally, rig cost, $\mathrm{mud} / \mathrm{measure}$ while drilling (MWD) cost, and connection/trip times were entered into the optimizer prior to generating the ARSL so a cost analysis can also be included. The ARSL is the main component of the drilling simulation and is used as the standard measurement of the unconfined compressive strength or the "drillability" of the formation [1].

This ARSL is generated by inverting the bit specific ROP drilling models to solve for the rock strength on a foot by foot basis [5]. Therefore, it is recommended that values obtained from the ARSL are verified with other rock strength estimation mechanisms to ensure there is no significant deviation between one another. This can be done by utilizing strength tests obtained from mechanical laboratory testing on rock cores, utilizing data interpretation from other logs, or cuttings obtained when drilling.

Unlike rock laboratory mechanical testing, the ARSL allows the user to know the rock strength at every foot of the wellbore determined while drilling. Therefore, the ARSL is the only form of testing that is capable of generating the in situ strength properties of the formations. The ARSL that is obtained could be used to simulate not only the "drillability" of the formations, but several other aspects of the petroleum engineering analysis. The predicted formation strengths could be used to estimate the minimum horizontal stress (Sh) along the wellbore [15]. These Sh estimations can be used to help with wellbore stability, completion design methods, and produced sand control in reservoirs [1].

\section{Developing the Simulation}

The ARSL generated from the reference well is used to simulate the upcoming or future well. Since the simulation must be conducted on wells within the same field, formation tops of the reference well are shrunk or expanded to fit the tops for the well that is being simulated [16]. Once the formation tops had been matched to fit the new well, the optimizer correlates the rock strength from the reference well for the upcoming well. This allows the optimizer to predict drilling time, bit wear, and operational parameters for the new well [11]. However, the simulation does not stop here.

The ultimate goal of developing a drilling simulation is to optimize the entire process so the lowest cost per foot is achieved [17]. Therefore, several simulations need to be conducted for every section of the wellbore to ensure the optimum parameters are achieved. This includes different scenarios of WOB/RPM, adjusting drilling parameters for changes in ARSL, bit type and hydraulics, drilling fluid type and rheology, and drilling modes.

The best method to increase the ROP of the entire drilling operation is to separate different sections of the wellbore. Sections are divided based off changes in lithology or rock strength. A sensitivity analysis should be conducted to see the effect of changing operational parameters, equipment specifications or type has on the drilling rate. The ultimate goal of conducting a sensitivity analysis is to see the effects changing parameters has on the ROP for that section but most importantly the overall drilling performance for the entire well. 




FIgURE 5: ARSL generated for reference Well A.

\section{Results}

The results of this work are presented in two parts. First, we present the results achieved from simulating Well B and Well C using offset reference well data. Well B was simulated using one well for reference while Well $\mathrm{C}$ was simulated using two wells for reference. Second, we present the results of optimizing all three proposed wells by finding the best combinations of WOB, RPM, and hydraulics. Furthermore, an analysis was conducted to see the potential benefits that could be obtained by the operator from utilizing drilling performance modeling applied in the optimizer to simulate upcoming wells within the same field.

\section{Simulation Validation}

The objective of validating the simulations was first to determine the accuracy of simulating wells by utilizing offset well data within the proposed Northwest Louisiana field. Well B was simulated utilizing the drilling files generated from Well A. First, the ARSL of Well A was generated after necessary data files were created (Figure 5). Then, the formation tops of Well A were formatted to fit the tops for Well B. The operating parameters applied during drilling operations of Well B were entered into the optimizer to produce the simulation. The simulated results were then compared with the actual results of Well B (Figure 6).

Figure 6 presents a good visual match with the simulations produced in the optimizer. The average ROP for the entire well was estimated to be $85.96 \mathrm{ft} / \mathrm{h}$ when the actual was approximately $100.89 \mathrm{ft} / \mathrm{h}$ giving approximately an $84 \%$ match. While a $16 \%$ difference is not as accurate as was expected there are some sources of error that should be noted. While the formations encountered are the same, there is some variation between the lithologic percentages as shown in Figure 6. The last formation simulated using Well A has much less sand concentrations than Well B. This is most likely attributed due to a slight change in the depositional processes. In addition, when only one well is used for reference the simulation produced takes into account a wider range for the ARS and ROP. This is clearly visible when comparing the ARSL of the simulated and actual in Figure 6.

The simulation of Well $\mathrm{C}$ was produced by utilizing both Well A and Well B as reference wells. Formation tops of the ARSL were formatted to fit those for Well C. The simulation for Well $\mathrm{C}$ was generated by inputting the operational parameters used when Well $\mathrm{C}$ was drilled. The comparison between the simulated and actual results is presented in Figure 7.

Figure 7 presents a much closer match than shown previously for the simulation of Well $\mathrm{B}$. The average ROP for Well $\mathrm{C}$ was simulated to be $67.16 \mathrm{ft} / \mathrm{h}$ while the actual was approximately $67.42 \mathrm{ft} / \mathrm{h}$ giving a match of approximately $99 \%$. This study cannot guarantee that all simulated results will be as accurate as Well C. However, by comparing the simulations of Well B and Well C it can be assumed that as more wells are added for reference, the accuracy of the simulations will continue to increase. This is due to the reduction in discrepancies seen between wells.

\section{Optimization}

Once the wells were simulated for this Northwest Louisiana field, each section was optimized to find the best operating 


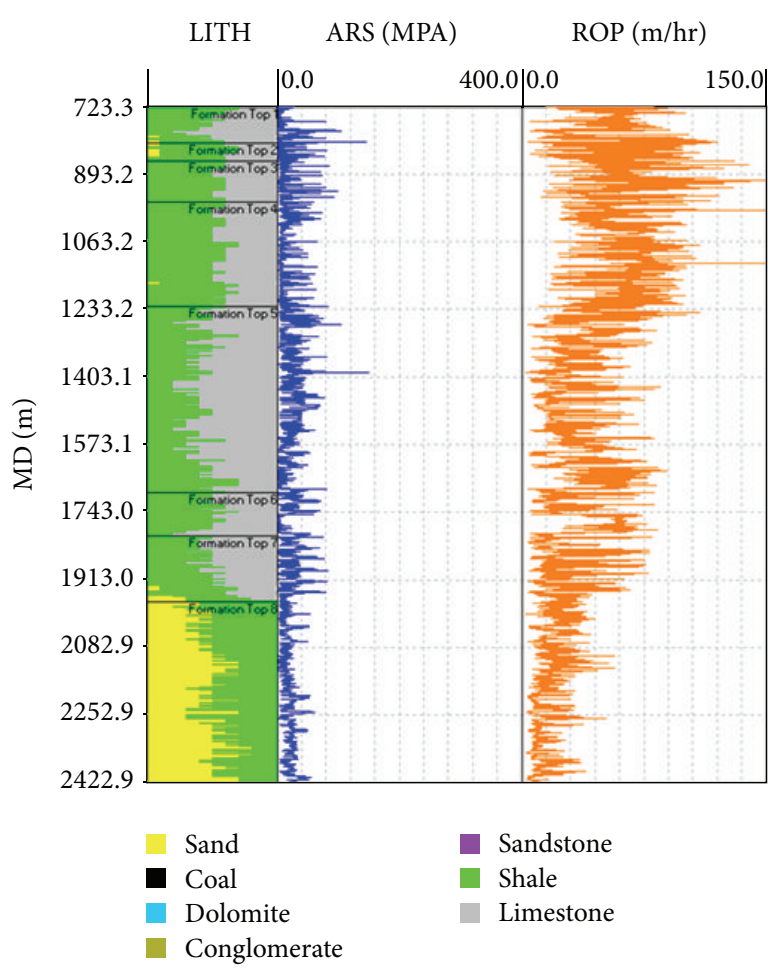

(a)

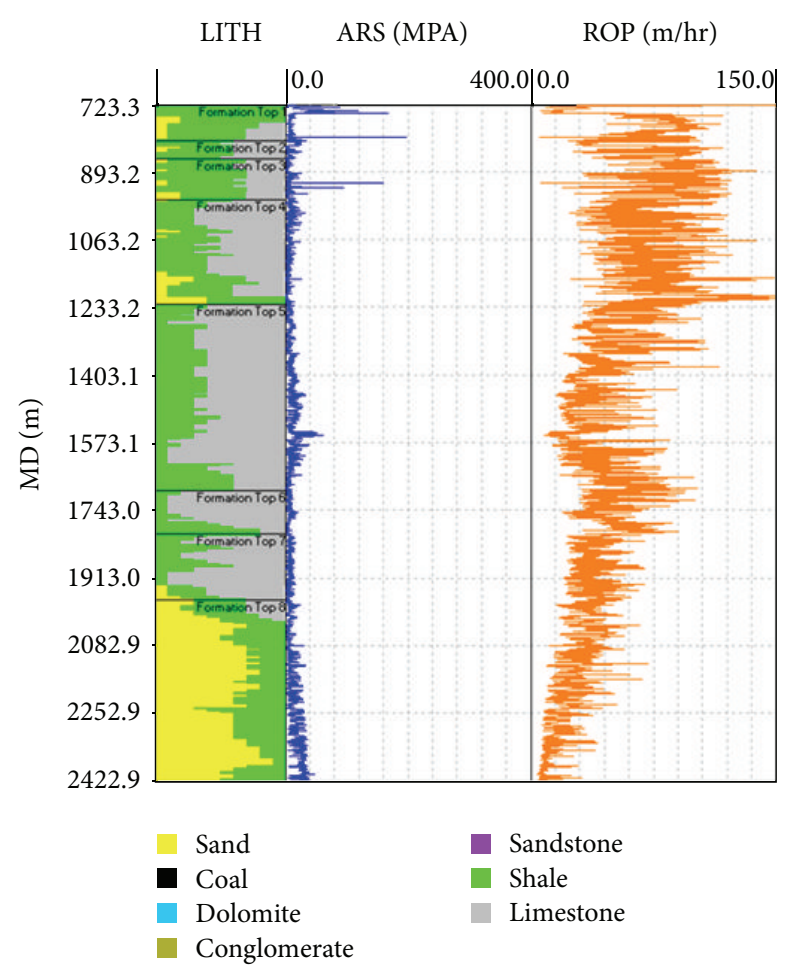

(b)

FIgURE 6: Comparison of the simulation (a) to the actual (b) for Well B.



(a)

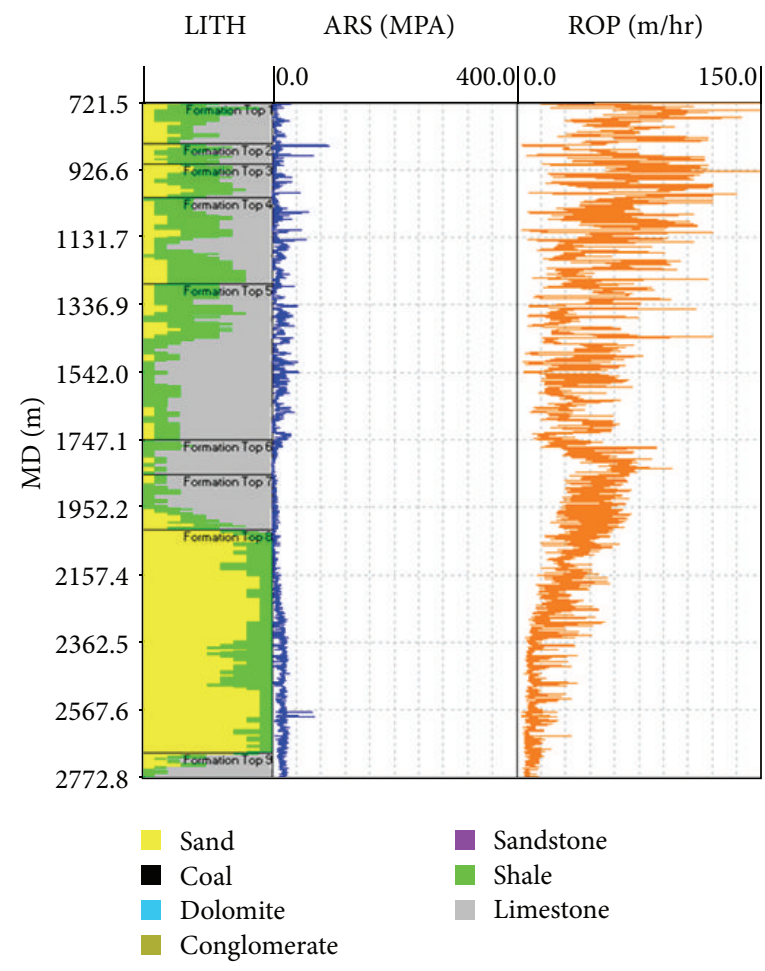

(b)

Figure 7: Comparison of the simulation (a) to the actual (b) for Well C. 
TABLE 1: Optimized parameters for Well A.

\begin{tabular}{|c|c|c|c|c|c|c|c|c|}
\hline \multicolumn{9}{|c|}{ Well A sensitivity analysis results } \\
\hline Formation & Top (ft) & Bottom $(\mathrm{ft})$ & $\mathrm{ROP}(\mathrm{ft} / \mathrm{h})$ & WOB (k-lbs) & RPM & $\mathrm{FR}$ (gal/min) & $\mathrm{PV}(\mathrm{cp})$ & MW (ppg) \\
\hline 1 & 2401 & 2628 & 324.64 & 12 & 75 & 555 & 12 & 8.5 \\
\hline 2 & 2628 & 2785 & 269.78 & 10 & 75 & 591 & 12 & 8.5 \\
\hline 3 & 2785 & 3123 & 300.36 & 13 & 85 & 594 & 12 & 8.6 \\
\hline 4 & 3123 & 3970 & 176.02 & 16 & 80 & 597 & 13 & 8.8 \\
\hline 5 & 3970 & 5515 & 94.88 & 20 & 70 & 592 & 14 & 9.3 \\
\hline 6 & 5515 & 5890 & 125.92 & 26 & 90 & 600 & 17 & 9.6 \\
\hline 7 & 5890 & 6426 & 83.20 & 26 & 82 & 580 & 17 & 9.6 \\
\hline 8 & 6426 & 8698 & 58.69 & 30 & 55 & 540 & 16 & 10.0 \\
\hline 9 & 8698 & 8925 & 49.11 & 34 & 55 & 540 & 17 & 10.4 \\
\hline 10 & 8925 & 8999 & 53.11 & 30 & 55 & 540 & 18 & 10.4 \\
\hline
\end{tabular}

TABLE 2: Well A optimization savings potential.

\begin{tabular}{|c|c|c|c|c|}
\hline & $\mathrm{ROP}(\mathrm{ft} / \mathrm{h})$ & Time (hours) & Cost per foot & Total costs \\
\hline Real & 55.45 & 111.00 & $\$ 168.70$ & $\$ 1,034,097.34$ \\
\hline Optimized & 84.38 & 78.20 & $\$ 129.66$ & $\$ 794,778.82$ \\
\hline Savings & 28.93 & 32.80 & $\$ 39.04$ & $\$ 239,318.52$ \\
\hline
\end{tabular}

parameters for each well. The focal point of the optimization process was to reduce drilling time and associated costs over the entire length of the $8.75^{\prime \prime}$ section while ensuring the bit does not exceed an IADC wear of 2.5.

The optimum operational parameters of Well A were found after conducting a sensitivity analysis (Table 1). Formations 1-4 should be drilled with a WOB ranging from 10 to $16 \mathrm{k}$-lbs with a rotary speed ranging from 75 to $85 \mathrm{rpm}$. WOB will slowly increase between 20 and $26 \mathrm{k}$-lbs while continuing a high rotary speed ranging from 70 to $90 \mathrm{rpm}$ for formations 5-6. Once arriving into the harder, more abrasive rock seen in formations 8-10, WOB should increase from 26 to $34 \mathrm{k}-\mathrm{lbs}$ while reducing the rotary speed to around $55 \mathrm{rpm}$. Utilizing these operational parameters for the formations shown in Table 1 will control the bit wear so the ROP is increased for the well.

The optimized bit, hydraulics, WOB/RPM, and combined optimization values were used to plot the time spent drilling versus the depth drilled (Figure 8). When the bit data used to drill Well A was changed to the specifications used for Well $\mathrm{B}$ and Well $\mathrm{C}$ the total drilling time was reduced by approximately 25 hours. Optimizing the hydraulics of the new bit reduced the total drilling time over another hour giving a total drilling time of approximately 94 hours compared to the actual of 121 hours. Finding the best combination of WOB and RPM parameters reduced the total drilling time over 43 hours from the original drilling time. When all parameters were combined the total drilling time was reduced by over 45 hours.

The economic impact of the optimized drilling parameters of Well A is presented in Table 2. Utilizing drilling performance modeling based off the drilling strength to find the most efficient parameters has the capability to save the operator approximately $\$ 239,318.52$ for the $8.75^{\prime \prime}$ vertical wellbore section of Well A.

The optimum operational parameters for Well B were found after conducting a sensitivity analysis (Table 3). Similar results are seen between Well A and Well B; however, since Well B was a shorter wellbore section higher WOB and RPM values can be implemented since bit wear does not have to be controlled as much. Formations 1-4 can be drilled using a WOB ranging from 14 to $16 \mathrm{k}$-lbs combined with a rotary speed from 75 to $85 \mathrm{rpm}$. WOB can be increased to $20-26 \mathrm{k}-$ lbs while rotary speed can be increased from 70 to $90 \mathrm{rpm}$ for formations 5-7. However, to ensure excessive bit wear does not occur before the end of the section is reached rotary speed should be reduced to $55 \mathrm{rpm}$ for formation 8 .

The effects of the optimized hydraulics, WOB/RPM, and combined optimization values for Well $\mathrm{B}$ were plotted to compare the time spent drilling versus depth drilled (Figure 9). When bit hydraulics were optimized the total drilling time was reduced by approximately 8 hours. Finding the best combination of WOB and RPM parameters did not have a significant effect on the drilling time. Optimizing the WOB/RPM parameters for Well B increased the drilling times for formations 1-7. However, by doing this bit wear was reduced so that the drilling time is reduced over the hard, abrasive lithology of formation 8 . When all parameters were combined the total drilling time was reduced by over 10 hours.

The economic impact of the optimized drilling parameters of Well B is presented in Table 4 . The operator could have potentially saved approximately $\$ 73,591.38$ for the 8.75 inch vertical wellbore section of Well $B$. This could be achieved from utilizing drilling performance models and offset well data. 

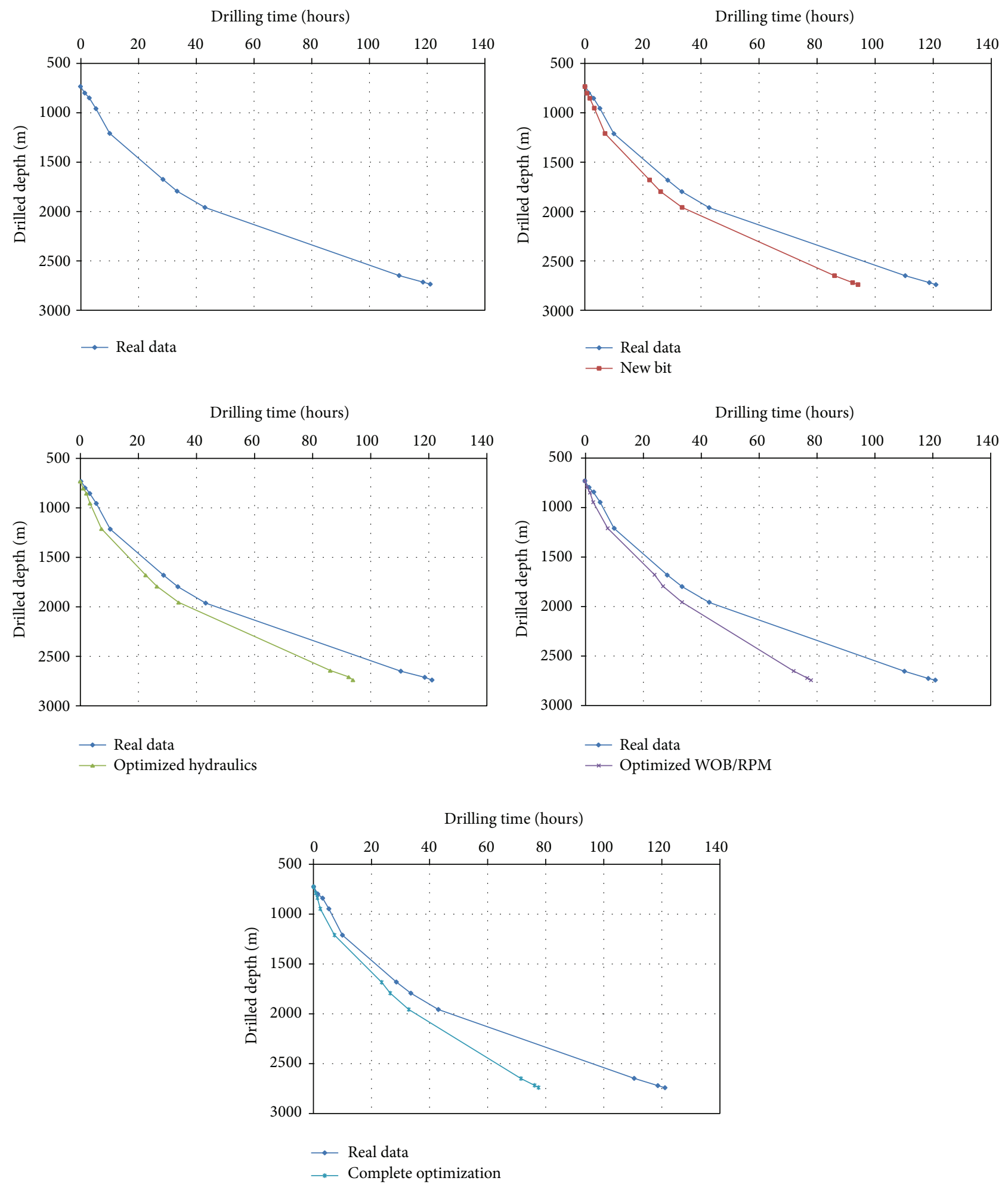

FIGURE 8: Drilling time versus drilled depth comparison with initial and optimized parameters for Well A.

The optimum operational parameters for Well $\mathrm{C}$ were found after conducting a sensitivity analysis (Table 5). The results of Well C are much similar to those of Well A since their designs are such a close match. Formation 1-4 should be drilled with WOB ranging from 10 to $16 \mathrm{k}$-lbs combined with a rotary speed of $75-85 \mathrm{rpm}$. WOB will increase from 20 to $26 \mathrm{k}$-lbs while rotary speed will vary from 70 to $90 \mathrm{rpm}$ for formations 5-7. When the harder, abrasive lithology seen in formations 8-9 is reached, WOB should be increased to $30-$ $34 \mathrm{k}-\mathrm{lbs}$ while rotary speed should be reduced to $55 \mathrm{rpm}$. 
TABLE 3: Optimized parameters for Well B.

\begin{tabular}{|c|c|c|c|c|c|c|c|c|}
\hline \multicolumn{9}{|c|}{ Well B sensitivity analysis results } \\
\hline Formation & Top (ft) & Bottom (ft) & $\mathrm{ROP}(\mathrm{ft} / \mathrm{h})$ & WOB (k-lbs) & RPM & $\mathrm{FR}(\mathrm{gal} / \mathrm{min})$ & $\mathrm{PV}(\mathrm{cp})$ & MW (ppg) \\
\hline 1 & 2373 & 2678 & 166.57 & 14 & 75 & 555 & 8 & 8.5 \\
\hline 2 & 2678 & 2820 & 193.08 & 14 & 75 & 581 & 9 & 8.6 \\
\hline 3 & 2820 & 3160 & 295.90 & 16 & 85 & 594 & 9 & 8.6 \\
\hline 4 & 3160 & 4022 & 262.07 & 16 & 80 & 597 & 8 & 8.7 \\
\hline 5 & 4022 & 5555 & 140.32 & 20 & 70 & 592 & 9 & 9.1 \\
\hline 6 & 5555 & 5910 & 212.27 & 26 & 90 & 594 & 9 & 9.2 \\
\hline 7 & 5910 & 6460 & 161.25 & 26 & 82 & 555 & 9 & 9.4 \\
\hline 8 & 6460 & 7949 & 67.81 & 30 & 55 & 542 & 11 & 9.7 \\
\hline
\end{tabular}

TABLE 4: Well B optimization savings potential.

\begin{tabular}{lcccc}
\hline & ROP $(\mathrm{ft} / \mathrm{h})$ & Time $($ hours $)$ & Cost per foot & Total costs \\
\hline Real & 100.89 & 55.07 & $\$ 107.92$ & $\$ 601,817.74$ \\
Optimized & 123.95 & 44.97 & $\$ 94.73$ & $\$ 528,226.36$ \\
Savings & $\mathbf{2 3 . 0 6}$ & $\mathbf{1 0 . 1 0}$ & $\mathbf{\$ 1 3 . 1 9}$ & $\mathbf{\$ 7 3 , 5 9 1 . 3 8}$ \\
\hline
\end{tabular}
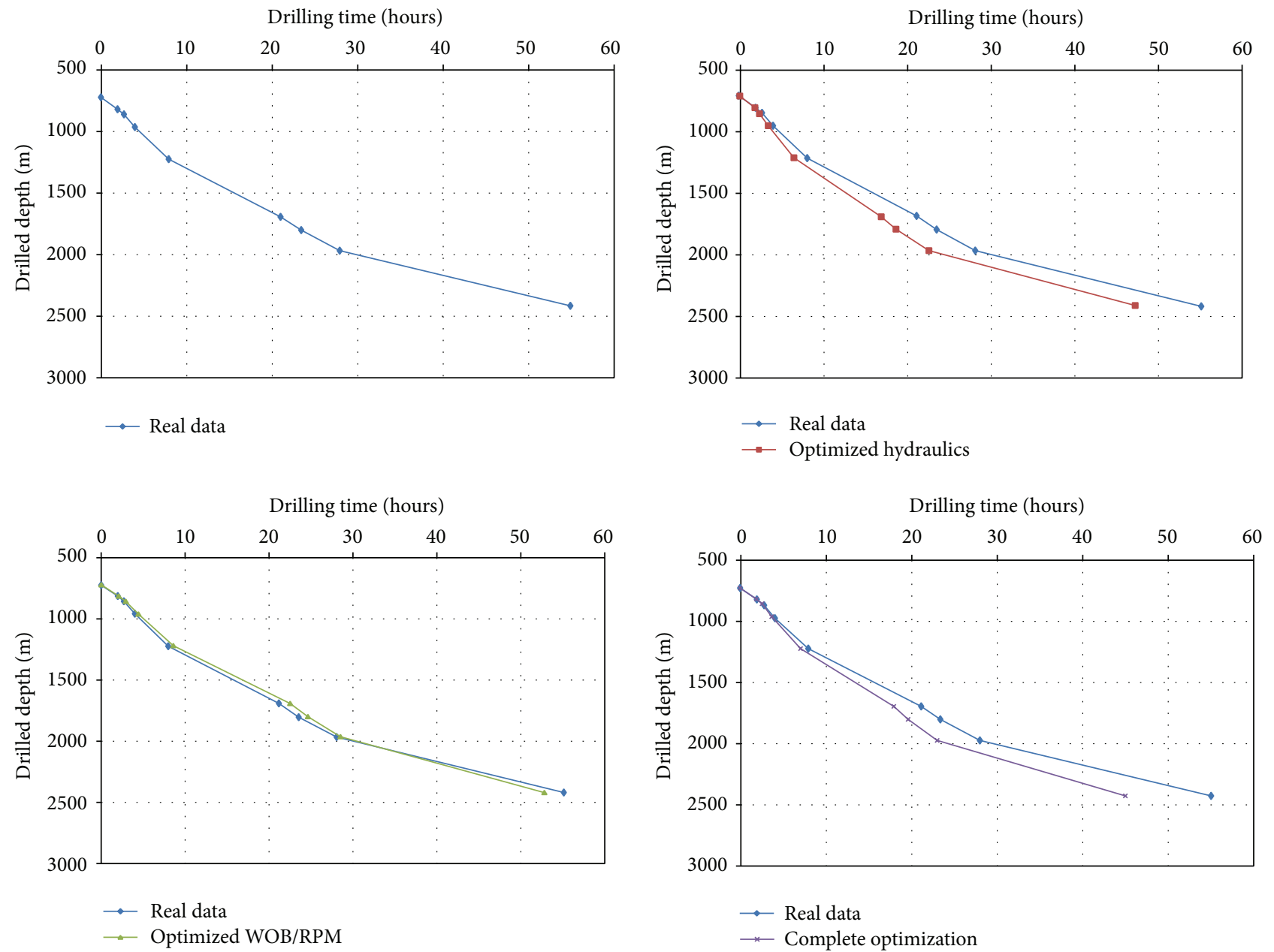

FIGURE 9: Drilling time versus drilled depth comparison with initial and optimized parameters for Well B. 
TABLE 5: Optimized parameters for Well C.

\begin{tabular}{|c|c|c|c|c|c|c|c|c|}
\hline \multicolumn{9}{|c|}{ Well C sensitivity analysis results } \\
\hline Formation & Top (ft) & Bottom (ft) & $\mathrm{ROP}(\mathrm{ft} / \mathrm{h})$ & WOB (k-lbs) & $\mathrm{RPM}$ & $\mathrm{FR}$ (gal/min) & $\mathrm{PV}(\mathrm{cp})$ & MW (ppg) \\
\hline 1 & 2367 & 2778 & 245.70 & 12 & 75 & 555 & 8 & 8.5 \\
\hline 2 & 2778 & 2982 & 121.06 & 10 & 75 & 592 & 8 & 8.6 \\
\hline 3 & 2982 & 3320 & 222.74 & 13 & 85 & 594 & 9 & 8.6 \\
\hline 4 & 3320 & 4173 & 146.72 & 16 & 80 & 594 & 9 & 8.9 \\
\hline 5 & 4173 & 5730 & 95.21 & 20 & 70 & 592 & 9 & 9.3 \\
\hline 6 & 5730 & 6083 & 209.25 & 26 & 90 & 599 & 10 & 9.5 \\
\hline 7 & 6083 & 6633 & 184.09 & 26 & 82 & 581 & 11 & 9.7 \\
\hline 8 & 6633 & 8853 & 49.70 & 30 & 55 & 594 & 13 & 9.8 \\
\hline 9 & 8853 & 9097 & 30.64 & 34 & 55 & 594 & 12 & 10.3 \\
\hline
\end{tabular}

TABLE 6: Well C optimization savings potential.

\begin{tabular}{lcccc}
\hline & ROP $(\mathrm{m} / \mathrm{h})$ & Time $($ hours $)$ & Cost per foot & Total costs \\
\hline Real & 67.42 & 103.74 & $\$ 154.81$ & $\$ 1,041,860.35$ \\
Optimized & 79.79 & 84.34 & $\$ 125.21$ & $\mathbf{\$ 8 4 2 , 6 7 8 . 1 5}$ \\
Savings & $\mathbf{1 2 . 3 7}$ & $\mathbf{1 9 . 3 9}$ & $\mathbf{\$ 2 9 . 6 0}$ & $\mathbf{\$ 1 9 9 , 1 8 2 . 2 0}$ \\
\hline
\end{tabular}


FIgURE 10: Drilling time versus drilled depth comparison with initial and optimized parameters for Well C. 
The effects of the optimized hydraulics, WOB/RPM, and combined optimization values for Well C were plotted to compare the time spent drilling versus depth drilled (Figure 10). When bit hydraulics were optimized the total drilling time was reduced by approximately 5 hours. Finding the best combination of WOB and RPM parameters reduced the drilling time from 107 hours to 87 hours. When all parameters were combined the total drilling time was reduced by approximately 20 hours.

The economic impact of the optimized drilling parameters of Well $\mathrm{C}$ is presented in Table 6. Utilizing drilling performance modeling and offset well data to simulate wells until the most efficient parameters could potential save the operator approximately $\$ 199,182.20$ for the $8.75^{\prime \prime}$ vertical wellbore section of Well C.

\section{Conclusions}

This paper presented a systematic approach to simulate and optimize the operational plan for upcoming wells using offset well data for a field in Northwest Louisiana. The following conclusions can be drawn:

(i) Comparison of the simulated and actual results of the proposed wells shows simulating upcoming wells using formation strength estimates from offset well data applied with optimizer is accurate for this Northwest Louisiana field.

(ii) Drilling performance simulations produced for Well B and Well C were $84 \%$ and $99 \%$ accurate with the actual results.

(iii) Comparing the differences in the accuracy of the simulations for Well B and Well C proves that as more wells are included for reference data, discrepancies between the predicted and actual drilling performance are reduced.

(iv) Applying drilling performance modeling based on formation strength is effective in ensuring optimum equipment and operational parameters are implemented prior to the drilling of a well in this Northwest Louisiana field.

(v) The results of the optimized bit, hydraulics, and WOB/RPM for Well A, Well B, and Well C could potentially reduce the time spent drilling by 32.80 , 10.10 , and 19.39 hours, respectively.

(vi) Had optimum operational parameters been implemented the operator could have potentially saved $\$ 239,318.52, \$ 73,591.38$, and $\$ 199,182.20$ for Well A, Well B, and Well C.

\section{Conflict of Interests}

The authors declare that there is no conflict of interests regarding the publication of this paper.

\section{Acknowledgment}

Authors would like to thank Pason Systems Corp. for supporting and giving access to use optimizer for educational purposes.

\section{References}

[1] G. Hareland, H. R. Motahhari, J. P. Hayes, and A. Qureshi, "Increased drilling-efficiency of gas-storage wells proven using drilling simulator," in Proceedings of the CIPC/SPE Gas Technology Symposium, Paper SPE 114798, Calgary, Canada, June 2008.

[2] T. Berre, L. Tunbridge, and K. Hoeg, "The measurement of small strains and K0-values in triaxial tests on clay-shales," in Proceedings of the 8th International Congress on Rock Mechanics, pp. 1195-1199, Tokyo, Japan, 1995.

[3] F. Zausa, L. Civolani, M. Brignoli, and F. J. Santarelli, "Real-time wellbore stability analysis at the rig-site," in Proceedings of the SPE/IADC Drilling Conference, Paper SPE 37670, Amsterdam, The Netherlands, March 1997.

[4] K. Tokle, P. Horsrud, and R. K. Bratli, "Predicting uniaxial compressive strength from log parameters," in Proceedings of the 61st Annual Technical Conference and Exhibition of the Society of Petroleum Engineers, Paper SPE 15645, New Orleans, Lo, USA, October 1986.

[5] P. R. Rampersad, G. Hareland, and P. Boonyapaluk, "Drilling optimization using drilling data and available technology," in Proceedings of the 3rd Latin American/Caribbean Petroleum Engineering Conference, Paper SPE 27034, Buenos Aires, Argentina, April 1994.

[6] W. C. Maurer, “The perfect-cleaning theory of rotating drilling," in Proceedings of the 37th Annual Fall Meeting of SPE, Paper SPE 408, Los Angeles, Calif, USA, October 1962.

[7] G. Hareland, R. Nygaard, B. K. Virginillo, and H. B. Munro, "Drilling simulation improves field communication and reduces drilling cost in Western Canada," in Proceedings of the Petroleum Society's 8th Canadian International Petroleum Conference, Paper PETSOC 2007-086, Calgary, Alberta, Canada, June 2007.

[8] G. Hareland, W. Yan, R. Nygaard, and J. L. Wise, "Cutting efficiency of a single PDC cutter on hard rock," in Proceedings of the Petroleum Society's 8th Canadian International Petroleum Conference, Paper 2007-082, Calgary, Alberta, Canada, June 2007.

[9] R. Andrews, G. Hareland, R. Nygaard, T. Engler, H. Munro, and B. Virginillo, "Methods of logs to quantify drillability," in Proceedings of the SPE Rocky Mountain Oil and Gas Technology Symposium, Paper SPE 106571, Denver, Colo, USA, April 2007.

[10] A. T. Bourgoyne, K. K. Millheim, M. E. Chenevert, and F. S. Young, Applied Drilling Engineering, vol. 2 of SPE Textbook Series, 1986.

[11] R. Nygaard and G. Hareland, "Application of rock strength in drilling evaluation," in Proceedings of the SPE 10th Latin American and Caribbean Petroleum Engineering Conference, (LACPEC '07), pp. 86-92, Buenos Aires, Argentina, April 2007.

[12] R. K. Bratli, G. Hareland, F. Stene, G. W. Dunsaed, and G. Gjelstad, "Drilling optimization software verified in the North Sea," in Proceedings of the SPE LACPEC Conference, Paper SPE 39007, Rio de Janeiro, Brazil, September 1997.

[13] E. C. Onyia, "Relationships between formation strength, drilling strength, and electric log properties," in Proceedings of 
the 63rd Annual Technical Conference and Exhibition of the Society of Petroleum Engineers, Paper SPE 18166, Houston, Tex, USA, October 1988.

[14] M. Fazaelizadeh, B. Rashidi, and G. Hareland, "Drilling-derived rock strength can simulate upcoming well performance," in Proceedings of the Canadian Unconventional Resources and International Petroleum Conference, SPE-135857-MS, Society of Petroleum Engineers, Calgary, Canada, October 2010.

[15] L. Song and G. Hareland, "Minimum horizontal stress profile from rock strength for montney formation in North East British Columbia Canada," in Proceedings of the 47th US Rock Mechanics/Geomechanics Symposium, Paper ARMA 13-141, San Francisco, Calif, USA, June 2013.

[16] M. Rastegar, G. Hareland, R. Nygaard, and A. Bashari, "Optimization of multiple bit runs based on ROP models and cost equation: a new methodology applied for one of the Persian gulf carbonate fields," in Proceedings of the IADC/SPE Asia Pacific Drilling Technology Conference and Exhibition, Paper IADC/ SPE 114665, Jakarta, Indonesia, August 2008.

[17] G. Gjelstad, G. Hareland, K. N. Nikolaisen, and R. K. Bratli, “The method of reducing drilling costs more than 50 percent," in Proceedings of the SPE/ISRM Eurock, Paper SPE/ISRM 47342, Trondheim, Norway, July 1998. 

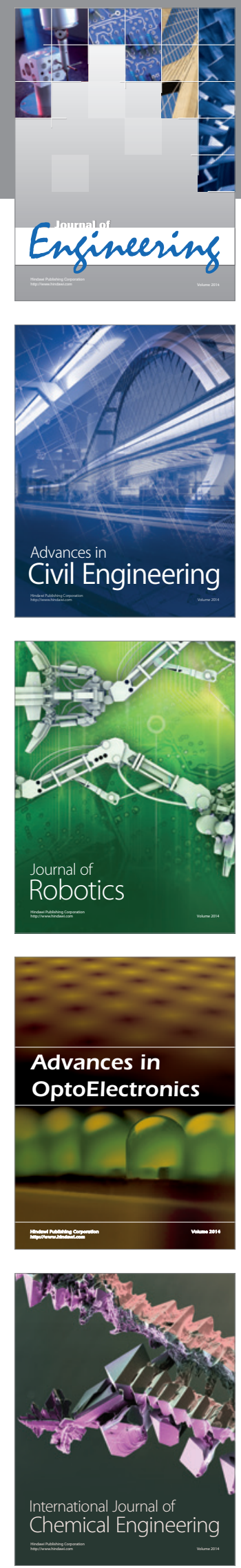

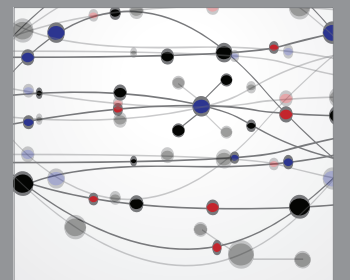

The Scientific World Journal
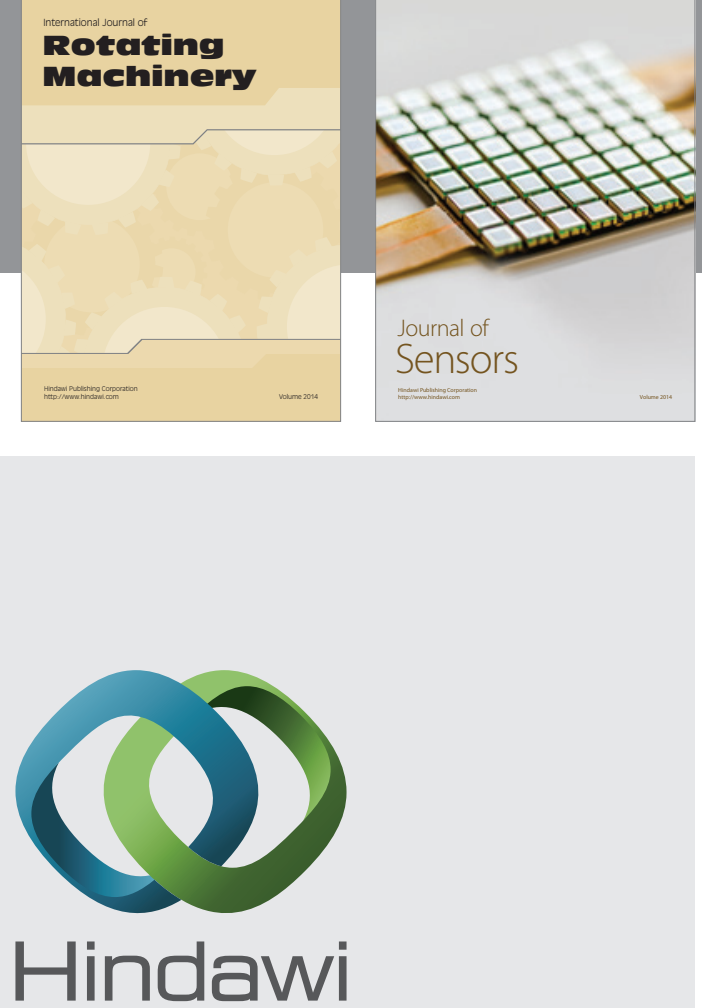

Submit your manuscripts at http://www.hindawi.com
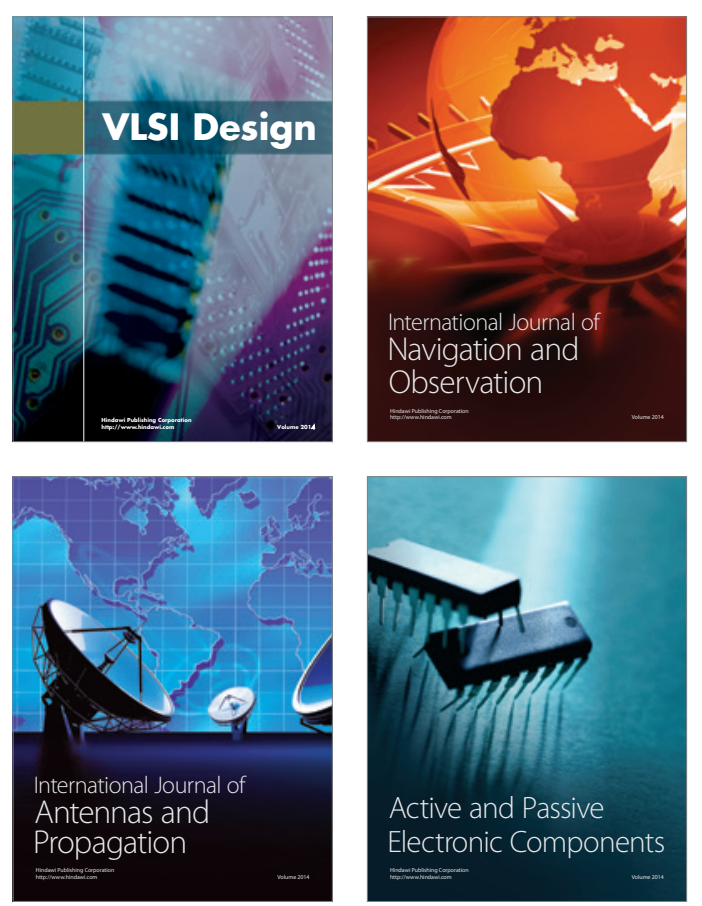
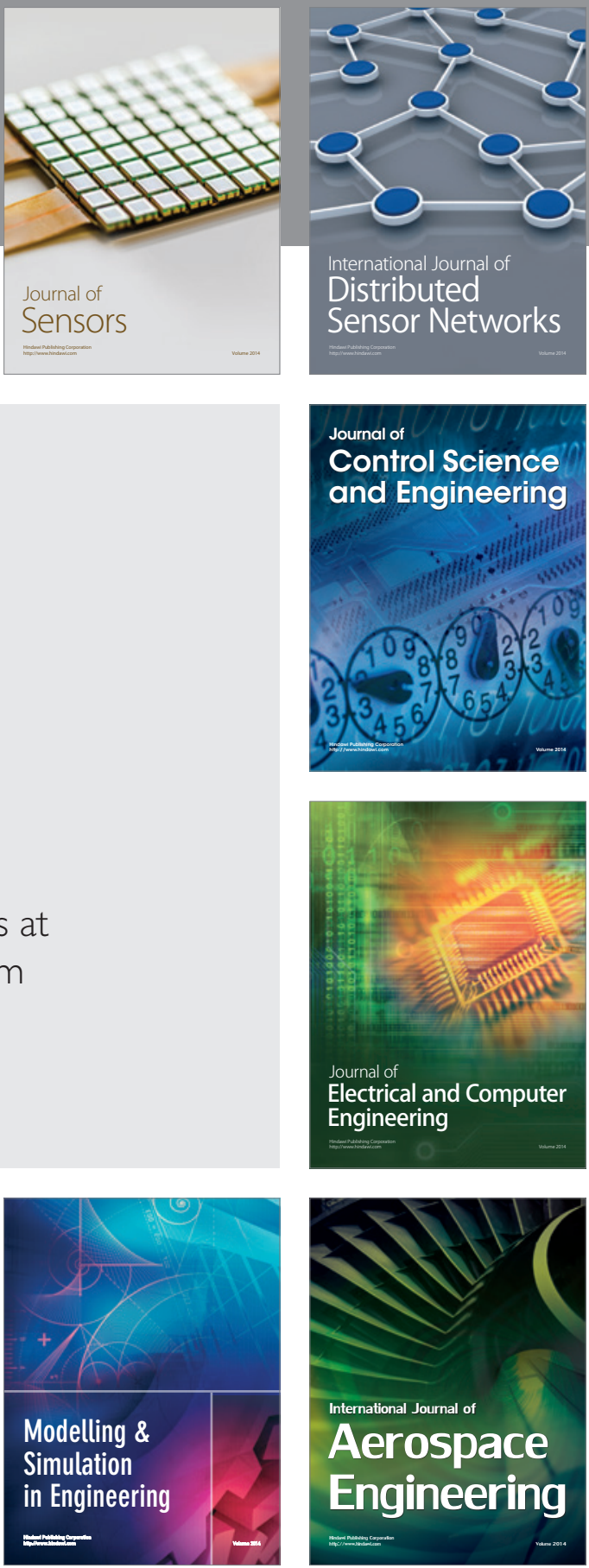

Journal of

Control Science

and Engineering
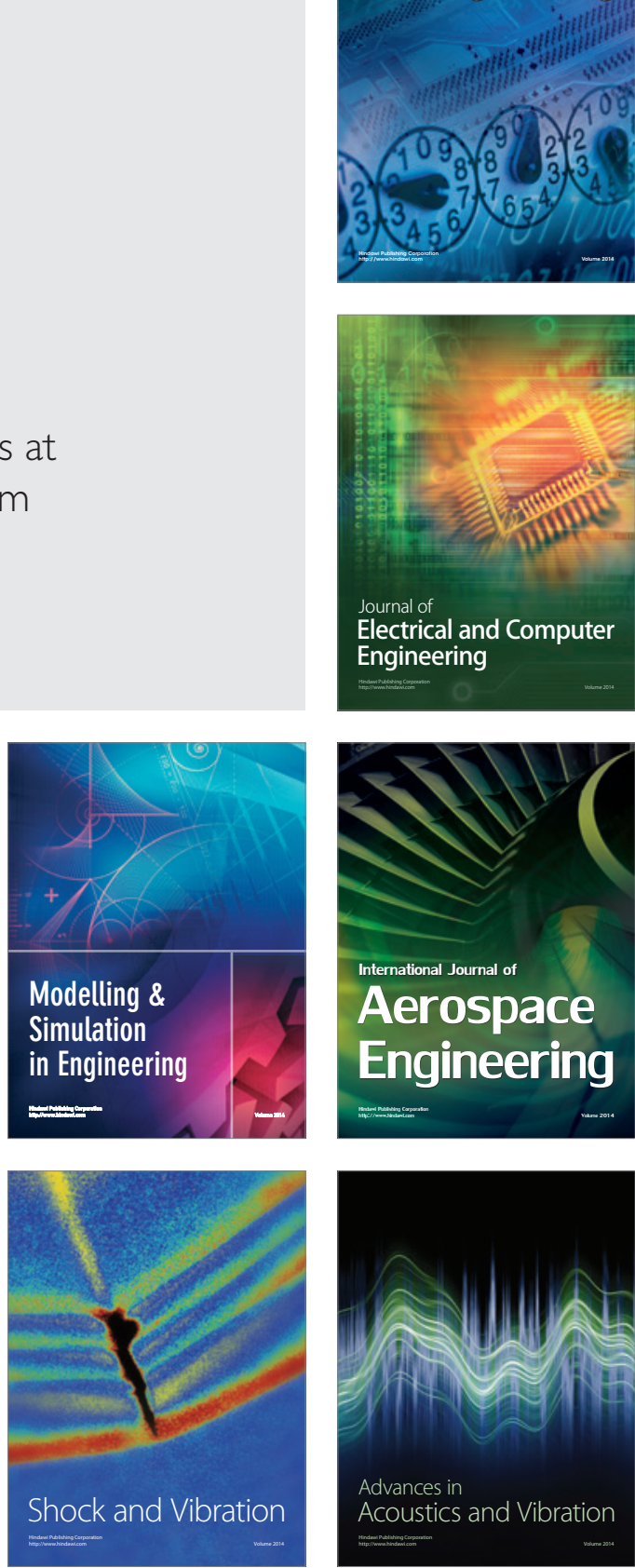